\title{
Sobre coautoria, produtivismo e performatividade: um exercício crítico-hermenêutico
}

\author{
Murilo Mariano Vilaça* \\ Alexandre Palma**
}

\begin{abstract}
Resumo: Neste artigo, abordamos o tema da colaboração acadêmico-científica por meio de coautoria no contexto atual marcado pela pressão por publicação. A partir da problematização do texto de Lopes e Costa (2012), nosso objetivo é desenvolver uma análise hermenêutica e crítica do tema através da revisão da literatura especializada e de uma reflexão teórica, a fim de prover elementos para a compreensão de uma prática tida como complexa. Como conclusão, inferimos que a prática de coautoria, dada a sua importância e caracterização, demanda abordagens teórico-empíricas cuidadosas e sistemáticas, o que ainda não tem sido feito na área de educação.
\end{abstract}

Palavras-chave: Educação. Coautorias. Produtivismo. Performatividade.

\section{On co-authorship, produtivism, and performativity: a hermeneutic and critical exercise}

\begin{abstract}
In this paper, we approach the issue of academic and scientific collaboration through co-authorship in the current context typified by the pressure to publish. From the problematization of the paper by Lopes and Costa (2012), our goal is to develop a critical-hermeneutic analysis of the subject by reviewing the literature and a theoretical reflection, in order to provide elements for understanding of a practice seen as complex. In conclusion, we infer that the practice of co-authorship, given its importance and characterization, demand an careful and systematic theoretical and empirical approaches, which has not been done in the education field.
\end{abstract}

* Doutor em Filosofia pela Universidade Federal do Rio de Janeiro. Pesquisador da Fundação Oswaldo Cruz.E-mail: murilovilaca@fiocruz.br

** Doutor em Saúde Pública pela Escola Nacional de Saúde Pública da Fiocruz. Professor da Universidade Federal do Rio de Janeiro._E-mail: palma_alexandre@yahoo.com.br 
Keywords: Education. Co-Authorship. Produtivism. Performativity.

\section{Acerca de coautoría, productivismo y performatividad: um ejercício hermenêutico y crítico}

Resumen: En este artículo se aborda la cuestión de la colaboración académica y científica a través de coautoría en el contexto actual marcado por la presión por publicar. Al cuestionar el artículo de Lopes texto y Costa (2012), nuestro objetivo es desarrollar un análisis hermenéutico y crítica del tema mediante la revisión de la literatura y de una reflexión teórica, con el fin de proporcionar elementos para la comprensión de una práctica considerada compleja. En conclusión, se deduce que la práctica de la coautoría, por su importancia e caracterización, requiere enfoques teóricos y análisis empíricos de manera cuidadosa y sistemática, que no se ha hecho en el área de la educación.

Palavras clave: Educación. Coautoría. Productivismo. Performatividad.

\section{Introdução}

Em texto publicado recentemente, Lopes e Costa (2012) abordam o tema das colaborações acadêmico-científicas via coautoria, o que parece ser uma novidade na área de educação, ${ }^{1}$ haja vista esta não desenvolver estudos sistemáticos sobre o tema. A prática acadêmico-científica da coautoria tem sido um dos alvos de reflexão dos estudiosos da cientometria e bibliometria vigentes. Para alguns, ela estaria sendo instrumentalizada como uma estratégia produtivista, em razão de uma verdadeira bolha inflacionária formada em torno dela (CAMARGO JR.; COELI, 2012).

O resumo do texto de Lopes e Costa revela o objetivo e o meio para alcançá-lo: eles querem "conhecer como vem desenvolvendo-se a

1 Na SciELO, utilizando as palavras-chave coautoria, colaboração acadêmica e colaboração científica, não encontramos texto especificamente sobre o tema proveniente da área de educação, à exceção do aqui abordado, embora haja diversos textos disponíveis procedentes de outras áreas. 
produção em coautoria na área de educação" através do levantamento "sobre a produtividade de 126 pesquisadores, seniores e categoria 1 do Conselho Nacional de Desenvolvimento Científico e Tecnológico (CNPq), no período de 2001 a 2010", a fim de defender "a valorização dessa forma de expressão dos resultados da colaboração científica, principalmente em sua possibilidade de contribuir para a melhor formação de novos pesquisadores" (LOPES; COSTA, 2012, p. 751). A tese é que a coautoria é uma "forma de expressão dos resultados da colaboração científica que merece ser mais valorizada por nós, especialmente em virtude de sua possibilidade de contribuir para a melhor formação de nossos mestrandos e doutorandos" (LOPES; COSTA, 2012, p. 720).

Defender a importância da 'desmonologização' da pesquisa e divulgação acadêmico-científica - por meio de coautorias, bem como, mais especificamente, o incremento da rede de colaboração entre professores (orientadores) e estudantes (orientandos), ampliando e estreitando os laços de compromisso, ressaltando o seu caráter pedagógico e formativo - é pertinente. Em que pesem pertinentes ressalvas - quanto, por exemplo, à possibilidade de a coautoria servir como uma estratégia de introdução e adequação de pós-graduandos à cultura do ready-to-write model (modelo "pronto para escrever") (ROLAND, 2007), mas, mormente, quanto às condições concretas para uma correta execução de coautorias, sobretudo com a função definida pelos autores - parece-nos razoável supor que dificilmente alguém apresentaria críticas radicais e absolutas ao valor da colaboração acadêmico-científica. Quer dizer, o valor, per si, desse tipo complexo de colaboração pode ser um ponto pacífico, mas o modo e com que finalidade, na prática, ela ocorre é caso de grande polêmica.

No artigo, é afirmado que "por intermédio da socialização dos textos e das múltiplas e imprevisíveis leituras que deles são feitas, outras equivalências podem vir a ser constituídas, ampliando as redes de colaboração e contribuindo para hegemonizar determinados discursos" (LOPES; COSTA, 2012, p. 726). Reconhecendo o valor do tema em discussão e motivados por essas palavras, visamos a dar publicidade a uma 
das múltiplas leituras possíveis, estabelecendo outras equivalências entre teoria e prática, dados e conclusões, hipóteses e teses, ampliando a rede de reflexão sobre um tema tão importante quanto o analisado por eles e contribuindo, quiçá, para a construção de outras hegemonias discursivas.

Inobstante a relevância do tema abordado, para nós, o texto merece atenção crítica, haja vista possuir aspectos controvertidos que, no nosso entendimento, são defendidos mais com um teor assertivo do que argumentativo ou demonstrativo. Há, por parte dos autores, uma importante, e, talvez, proposital subvalorização de fatores citados e analisados na vasta e recente literatura especializada sobre os temas que eles abordam, a qual mostra, com profusão, a grande relevância de investigar o fenômeno da multiplicação das coautorias, na medida em que elas têm sido uma das estratégias produtivistas. A justa opção dos autores de pôr em relevo a observação de que "a coautoria não está sendo utilizada obrigatoriamente para ampliar a produção" (LOPES; COSTA, 2012, p. 722, grifo nosso), pode, como argumentamos adiante, subvalorizar os reais problemas em torno da inflação das coautorias (CAMARGO JR.; COELI, 2012). Outro ponto controverso é o apoio numérico/estatístico das afirmações e conclusões explicitadas no texto, especialmente quanto à suposta inexistência do produtivismo na área de educação. A seleção de artigos para forjar um efeito de consenso em torno da positividade da ampliação das redes de colaboração científica, a inexata demonstração e algumas retorquíveis associações de autores e ideias também merecem crítica.

Conquanto, o objetivo declarado seja o supracitado, parece-nos que os autores têm outras e, quiçá, maiores pretensões, as quais tomam relevante espaço do texto, servindo ora de apoio para aquele alvo declarado, ora assumindo maior destaque. A título de provocação da reflexão e do debate acadêmicos, consideraremos como a 'outra mira' - por sinal, sobremaneira mais polêmica - para a qual estaria voltado seu maior esforço argumentativo.

Nosso exercício crítico-hermenêutico visa a identificar os alvos dos autores e compreender o modo como são abordados, problematizando 
algumas das suas afirmações, premissas e inferências. Por meio da seleção de pontos que nos parecem mais polêmicos, contra-arrazoaremos, fornecendo elementos para uma reflexão sobre o tema. Simultaneamente, revisamos a recente literatura especializada e desenvolvemos uma reflexão teórica, almejando à ampliação e melhor compreensão da complexa prática em tela.

Em conformidade com as conclusões de Glänzel e Schubert, partimos das premissas de que: (1) fatores políticos e econômicos atinentes à ideia de big science influenciam a lógica colaborativa, vez que a "colaboração científica é claramente estimulada (ou prejudicada) por interesses políticos nacionais, regionais ou globais" (GLÄNZEL; SCHUBERT, 2004, p. 272); (2) a "colaboração em pesquisa e a coautoria em ciência são fenômenos multifacetados" (GLÄNZEL; SCHUBERT, 2004, p. 273), assim, a maneira correta de compreendê-los e interpretá-los implica estudá-los "em cada nível de agregação em sua forma específica” (GLÄNZEL; SCHUBERT, 2004, p. 273); e (3) embora haja efeitos positivos da colaboração científica, "os benefícios, contudo, não vem automaticamente” (GLÄNZEL; SCHUBERT, 2004, p. 274), o que "reforça a necessidade de regular monitoramento quantitativo dos insumos e resultados, ou seja, de estudos biblométricos" (GLÄNZEL; SCHUBERT, 2004, p. 274).

Na seção abaixo, mapeamos e problematizando as afirmações dos autores. Visando à clareza, subdividimo-la em tópicos que, conquanto tenham nítidas ligações entre si, focalizam estratégias argumentativas ou traços discursivos específicos utilizados pelos autores, para que possamos apresentar nossas contra-argumentações de forma mais precisa possível.

\section{Sobre dados, afirmações e inferências: por uma hermenêutica crítica}

Os autores focalizam o tema do produtivismo desde o começo do artigo. Antes de abordar o tema da coautoria, eles se posicionam acerca da polêmica sobre a política acadêmico-científica e seus efeitos, retorquindo 
uma vertente na educação composta por distintos pesquisadores, referenciais e argumentos (KUENZER; MORAES, 2005; SGUISSARDI, 2006; SOUSA; BIANCHETTI, 2007; TREIN; RODRIGUES, 2011; BIANCHETTI; ZUIN, 2012) que repercutem facetas de uma tendência global de crítica aos efeitos produtivistas da cientometria e bibliometria vigentes.

Lopes e Costa (2012) esposam a política acadêmico-científica praticada pelo que Trein e Rodrigues (2011) denominam de sistema brasileiro de ciência e tecnologia, afirmando que as mudanças na pós-graduação em educação no país, aparentemente tidas como positivas, ocorreram "em virtude do caráter indutor das orientações estabelecidas pela avaliação de programas nas comissões de área da Coordenação de Aperfeiçoamento de Pessoal de Nível Superior (CAPES)" (LOPES; COSTA, 2012, p. 717). Cabe registrar, frente a essa aposta no sistema de avaliação, que esse caráter indutor tem sido alvo de múltiplas e mais ou menos severas críticas não só de pesquisadores da área de educação, mas também de tantas outras (CASTIEL; SANZ-VALERO, 2009; ALCADIPANI, 2011).

Tendo em vista os traços destacados, desenvolvemos nossa proposta de interpretação e crítica, a partir de uma postura político-ideológica e, portanto, de uma compreensão crítica da realidade distintas às sustentadas pelos autores, sem, contudo, assumir a posição extrema de que 'tudo está errado' e/ou de que não é preciso avaliar a produção acadêmico-científica de alguma forma. Mas entendemos que a lógica existente, de um mundo científico baseado em indicadores de performance que pautam o desafio da normalização - termo bem sugestivo e apropriado, por sinal - 'qualitativa' (PRATHAP; LEYDESDORF, 2012), tem gerado variados problemas, pois suas regras podem contribuir para ensejar práticas nocivas à Academia e ciência no Brasil, à semelhança do que se vê internacionalmente (ROLAND, 2007; FANELLI, 2010), devendo, portanto, ser refletida criticamente.

Coautorias: colaboração científica e/ou estratégia de conservatio vitae? 
Aparentemente, Lopes e Costa (2012) partem da premissa não argumentada de que o incremento quantitativo da produção bibliográfica é algo, em si, positivo. Para confirmá-la, eles citam artigos de algumas áreas, nos quais os autores apontam para o aumento das redes de colaboração como uma forma de incrementar a produtividade de pesquisadores e Programas de Pós-Graduação (PPGs) brasileiros. A passagem de uma afirmação a outra não é anunciada ou justificada, sugerindo o entendimento de que, pari passu, as coautorias são, em si, algo sempre positivo. Embora o objetivo dos autores seja mostrar o valor pedagógico e formativo das coautorias, há indícios, inclusive no próprio texto, que revelam algo distinto, isto é, que a coautoria tem sido utilizada de modos incorretos, como os apontados por Bartneck e Kokkelmans (2011) - autoria honorária, autocitação, coautoria compulsória entre pesquisadores de um mesmo instituto estimulada por seu diretor etc. - e/ou visando meramente ao aumento da produtividade e de índices de desempenho (como o Fator de Impacto e o Índice-H), o que, conforme Quimet, Bédard e Gélineau (2011), motiva estudos teórico-empíricos, sobretudo no campo da citation-analysis, que identificam o problema e desenvolvem meios de diminuir o peso da coautoria em tais índices.

Para ilustrar o que afirmamos e abordar alguns pontos que julgamos controversos, selecionamos alguns exemplos de duas áreas citadas (Administração e Ciências da Informação) pelos autores para afirmar a importância das coautorias, o que, esperamos, será capaz de dissolver qualquer tentativa de forjar um consenso. Um dos artigos que diz respeito à área de Administração, citado por Lopes e Costa (2012), é o de Melo, Crubellate e Rossoni (2010), sobre o qual é dito que "o aumento na cooperação científica foi gerador de um crescimento da produção em coautoria" (LOPES; COSTA, 2012, p. 718). Além de o aumento não fornecer, por si, nenhuma base para ajuizamentos sobre o valor da coautoria, os autores pressupõem "que a configuração da rede de coautorias, formada entre os professores vinculados aos programas pesquisados, pode oferecer indicativos das respostas à avaliação da Capes" (MELLO; CRUBELLATE; 
ROSSONI, 2010, p. 437). Ou seja, para eles, o aumento das colaborações pode ser uma mera resposta estratégica ao tipo de avaliação realizado pela CAPES, havendo uma relação íntima entre dois elementos, quais sejam redes de coautorias e respostas estratégicas. Ainda segundo eles, as determinações do contexto e a necessidade de alianças estratégicas que produzem valor estratégico e legitimidade são

aspectos (que) devem ser considerados nas relações formadas entre professores vinculados aos programas de pós-graduação (stricto sensu) em administração por meio de co-autorias, porquanto tais relacionamentos são influenciados, direta ou indiretamente, por pressões ambientais. Tais pressões interferem no comportamento dos pesquisadores que fazem parte dos programas, em um nível, assim como nas escolhas estratégicas dos programas, em outro nível, motivadas pelo ambiente no qual estão imersos (MELLO; CRUBELLATE; ROSSONI, 2010, p. 439).

Resta claro, portanto, que a conclusão mais plausível, se se considerar apenas esse artigo, é que os atores da área de administração têm se associado prioritariamente para dar conta da pressão gerada pela norma produtividade (VILAÇA; PALMA, 2013) implementada pela CAPES, a qual, segundo Bianchetti e Zuin, pauta-se, grosso modo, pela publicação de produtos acadêmicos, expressando o espírito de um tempo "que impinge o recrudescimento da quantidade em detrimento da qualidade de tais produtos", de modo que "o publish or perish parece ter atingido o paroxismo" (BIANCHETTI; ZUIN, 2012, p. 57).

Investigando a estruturação de cooperação entre PPGs de áreas da administração no Brasil por meio de coautorias, Rossoni e Guarido Filho verificam que elas apresentam uma estrutura do tipo small worlds, ligações preferenciais, centro-periferia e centralidade. Em suma, eles concluem que as redes de cooperação respeitam à lógica da estratificação da ciência, estabelecendo colaborações preferenciais através de critérios como citação, mérito científico, produtividade acadêmica, senioridade 
no campo, transferência de prestígio e legitimidade, acesso a recursos ou hierarquias de orientação, de modo que "atores preferenciais tendem a se tornar ainda mais centrais, atuando também como direcionadores dos desenvolvimentos teóricos a serem difundidos. Isso implica probabilidade de produção desigual de conhecimento" (ROSSONI; GUARIDO FILHO, 2009, p. 371). Há, conforme eles, o que podemos chamar de um círculo vicioso entre a centralidade dos PPGs, a quantidade de artigos publicados e o número de cooperações angariadas. Ou seja, as coautorias têm uma direção predominante, que é pautada por parâmetros afetos à cientometria e bibliometria vigentes, bem como pela expectativa, sobretudo dos PPGs periféricos, de que tais associações podem contribuir para a ascensão prestigiosa.

No artigo de Serra, Fiates e Ferreira (2008), vê-se um trecho em que o caráter pragmático das coautorias é novamente evidenciado, à medida que um professor (LM) considera que:

o tempo de R\&R (revisar e ressubmeter) médio em periódicos aumentou, enquanto a taxa de aceitação vem diminuindo. (...) Diante dessa constatação e da necessidade de publicação de uma média de dois artigos por ano, LM aconselha que se trabalhe em um número médio entre 5 e 8 artigos simultaneamente. Pensando nessa quantidade de artigos sugerida para trabalho simultâneo visando garantir a produtividade anual do pesquisador, o trabalho com co-autores passa a ser condição essencial para o sucesso na elaboração e publicação de artigos (FIATES; FERREIRA, 2008, p. 50; grifos nossos; trecho entre parênteses incluído).

Ainda sobre a área de Administração, ressaltamos que, para Freitas, não é de se estranhar que, no regime da produção em série:

o pesquisador seja estimulado a desenvolver algumas estratégias de sobrevivência. E aí podem se encontrar alguns comportamentos predatórios, tais como: os conluios espúrios para publicação, as alianças estratégicas do tipo "eu faço, ponho o seu nome; você faz, 
põe o meu nome", roubar ou plagiar ideias de colegas e alunos, obrigar orientandos a apontar coautorias indevidas ou nomear o orientador como primeiro autor indevidamente, etc. Esta instrumentalização dos vínculos (GUTIERREZ, 2005) propaga-se e se torna tão mais perigosa quanto mais ela é o exemplo que damos aos nossos orientandos ou alunos, que sequer começaram uma carreira. A mensagem é clara: vale a trapaça, a desfaçatez, a mediocridade, a conivência, a aceitação ou a publicação a qualquer preço (FREITAS, 2011, p. 1161; grifos nossos).

Alcadipani, ressaltando que o sistema produtivista não se rompe abruptamente, especialmente "sem que nada seja feito por aqueles que o sustentam, ou seja, nós os pesquisadores” (ALCADIPANI, 2011, p. 1176), afirma que importa perturbar, "gerar pequenas ou grandes perturbações no sistema, gerar mal-estar, incômodo, desconforto, escancarando o lado opressor desta situação, recusando-nos a nos submeter a esta lógica e, se preciso, pagando o preço por isso" (ALCADIPANI, 2011, p. 1176), por exemplo, recusando

a colocar o nome em trabalhos que não escrevemos e para os quais não demos nenhuma contribuição. Que fique claro, de uma vez por todas, o que significa autoria acadêmica - precisamos parar de aceitar que nossos colegas explorem os alunos. Hoje a produção acadêmica brasileira em Administração é feita em larga medida por alunos. Os professores precisariam voltar a pesquisar e a escrever de fato (ALCADIPANI, 2011, p. 1177).

Quanto à área de Ciência da Informação, Miranda, Simeão e Mueller afirmam que a autoria - logo, a coautoria - é uma instituição em crise. Eles citam o estudo de Antonio Braz de Oliveira Silva sobre coautorias no PPG em Ciência da Informação da Universidade Federal de Minas Gerais, cuja conclusão é que a produção conjunta entre professores e alunos se dá "por conta da avaliação ao qual é submetido e para concorrer ao financiamento de projetos de pesquisa, dentre outras coisas (SILVA, 
2006, p. 187)" (MIRANDA, SIMEÃO e MUELLER, 2007, p. 39). Noutro texto, que também é citado por Lopes e Costa (2012), Vilan Filho, Souza e Mueller (2008) ressaltam que sequer o significado do termo colaboração é claro e unívoco, tendo características específicas, inclusive dada a área de conhecimento, e gerando efeitos diferentes, o que é tido como ignorado pelos estudiosos do fenômeno e pelas autoridades científicas. Consoante eles, autorias múltiplas podem indicar, por si, apenas que os autores concordaram em partilhar a responsabilidade pelo texto.

Em face do que apresentamos aqui, não resta dúvida de que não é possível falar em consenso intra-áreas ou interáreas acerca da positividade das coautorias. Além disso, fica patente a realidade da prática de coautoria como algo instrumental ou estratégico, o que, inadvertidamente, o próprio texto de Lopes e Costa (2012) revela. As referências e afirmações citadas são insuficientes para comprovar que a ampliação do número de coautorias represente avanço, mormente no sentido defendido por eles. Isto posto, não está claro por que eles apostam tão firmemente nos avanços que o aumento das redes de colaboração já representariam, assim como por que desconsideram peremptoriamente a mencionada má influência da avaliação perpetrada pela CAPES sobre o que defendem.

Ressaltamos que a citação das referências supra não tem o objetivo de produzir um falto consenso em torno de uma espécie de absoluta negatividade das coautorias. Em vez disso, buscamos ressaltar a ambiguidade que recobre esta prática complexa. Nesse sentido, na tentativa de compreender a sua inscrição na realidade acadêmico-científica atual, recorremos à hermenêutica genealógica da política moderna desenvolvida por Esposito (2010), aplicando uma interpretação do paradigma da imunização.

Esposito utiliza esse paradigma para exprimir e entender um paradoxo dialético que caracteriza a constituição das sociedades modernas, o qual, na nossa interpretação, pode ser descrito utilizando uma analogia: na communitas (notadamente a sua versão antiga, que negava o indivíduo em nome do cum munus, ou seja, das relações gratuitas de doação 
recíproca, o "ser" e o "ter" tudo em comum) é inoculada uma espécie de agente patogênico, a saber, o indivíduo (noção tipicamente moderna, que estabelece um paradoxo com a comunidade), com a finalidade de atuar como um dispensatio temporário ou definitivo das obrigações e responsabilidades comunitárias gravosas, dando lugar à emergência de uma nova communitas, em que há práticas e estratégias de imunização do indivíduo. Daí a dialética modal não excludente positivo-negativo, conservador-destrutor, comunidade-indivíduo.

Quer dizer, "a imunização implica uma substituição, ou uma contraposição, pelos modelos privatísticos ou individualistas de uma forma de organização de tipo comunitário" (ESPOSITO, 2010, p. 80), já que o paradigma da imunização é o "reverso lógico da communitas - imune é o "não ser" ou o "não ter" nada em comum" (ESPOSITO, 2010, p. 81). Um tipo de associação humana não comunitária, em que é traçada uma espécie de linha divisória em torno do indivíduo, é marcado pela lógica relacional contratual. Nesta, como algum tipo de relação impõese, haja vista vivermos em grupo, os indivíduos sacrificam parte da sua liberdade e individualidade como uma estratégia de imunização (autopreservação) aos males da vida em comum. Assim, atenta ao problema da conservatio vitae, a imunização política nega a ordem comunitária na sua radicalidade, mas reafirma-a parcialmente, ou seja, naquilo que é útil ou necessária para preservar o indivíduo. Para Esposito, enquanto o paradigma comunitário apaga o indivíduo, o contrário não ocorre no paradigma da imunização. Voltada para a conservação do indivíduo, a imunização acaba produzindo algum efeito de conjunto, preservando, portanto, dada configuração comunitária. Aí o paradoxo e a dialeticidade que mencionamos, em que, para o filósofo, reside a vantagem da hermenêutica do paradigma imunitário para compreender a modernidade.

Analogamente ao paradoxo dialético communitas-imunizaçãocommunitas (numa nova conformação), haveria uma ambiguidade nos usos da coautoria. Um uso afirmaria a communitas acadêmico-cientifica, apostando nas colaborações obrigatórias e gratuitas frente ao fato do cum 
munus (da partilha de funções, dons, capacidades inerentes à condição humana), havendo um preterimento ou, no limite, um apagamento dos interesses estritamente individuais. Dito de modo breve, nele, reconhece-se a radical relação de dependência entre os indivíduos na busca pelo bem comunitário.

Por outro lado, haveria um uso estratégico da coautoria, por meio do qual o indivíduo visa a conservar a vida (acadêmico-científica) ante as demandas contextuais, o que tem um efeito recíproco. Nesse sentido, o indivíduo não colaboraria gratuitamente, pela, por assim dizer, natureza colaborativa do mundo acadêmico-científico, mas recorreria à coautoria como um meio de imunizar-se das penalidades afetas às políticas coletivas da (im)produtividade, reafirmando-as. Ou seja, o fim da colaboração não é o comum, mas o particular; não é a comunidade acadêmico-científica, mas a autoconservação. Neste uso, há o reconhecimento do valor estratégico da cooperação, buscando o bem individual, ainda que isso possa produzir males comunitários. Enfim, entendemos que a coautoria, como uma ação imunizatória, responde às regras comunitárias, as quais agem coativamente, ação que repercute sobre estas direta e mediatamente, dada a articulação antinômica envolvida.

A título de observação, essa hermenêutica que propomos, consoante Esposito, não endossa uma descontinuidade absoluta entre instâncias e usos. Para nós, é artificial a separação radical entre entes particulares (indivíduos) e entes coletivos (comunidades), já que alguma forma de relação entre eles é imperativa, pois são elementos que formam um único incindível, ainda que sua configuração seja historicamente mutável. Pensamos o mesmo quanto à cisão absoluta entre os usos das coautorias e seus efeitos, a qual seria simplória, vez que traços distintos podem imiscuir-se, gerando práticas e efeitos híbridos. Quer dizer, um uso imunizatório da coautoria pode produzir efeitos comunitários benéficos. Ademais, como estão envolvidos juízos de valor sobre os quais, para nós, não há consenso prévio, claro e universal, certas distinções podem ser retorquidas, dependendo da perspectiva. 


\section{Produtivismo e más condutas envolvendo coautoria: o que os números (não) podem revelar?}

Na introdução, Lopes e Costa afirmam que:

a tese de um produtivismo na área de educação não se justifica, caso consideremos os índices de produtividade bibliográfica dos programas de pós-graduação em educação - as instituições mais expressivas na produção do conhecimento educacional. Nos programas com conceitos de três a cinco, a média de produção docente por ano varia de 1 a 1,6 produto. Apenas nos programas nível seis, essa média atingiu o valor de dois por ano, no triênio 2007-2009 (LOPES; COSTA, 2012, p. 717-718).

Como uma das estratégias de persuasão mais eficazes no âmbito acadêmico-científico, o apoio de argumentos ou afirmações sobre números e percentuais costuma surtir um eficaz efeito retórico, ou seja, convencer o leitor de que aquilo que se diz é verdade. Talvez isso se justifique porque números tenham um caráter objetivo, real, imparcial, determinável e, para alguns, inquestionável. Ante a utilização de números e percentuais no texto em tela, resta claro que esta é uma estratégia argumentativa dos autores, o que é nosso alvo nesta seção.

Primeiramente, há números e percentuais citados que parecem conflitar com certas afirmações. Por exemplo, é informado que, entre 2001 e 2010, houve 1.615 produções envolvendo coautoria de orientador com orientando ou ex-orientando, o que representa $36 \%$ do total de coautorias no período. Os autores também afirmam que "a coautoria entre orientador e orientando ou ex-orientando parece estar aumentando com o passar do tempo. No período de 2006 a 2010, em relação ao período de 2001 a 2005 , houve um incremento de $58,4 \%$ na produção gerada pela colaboração professor-aluno" (LOPES; COSTA, 2012, p. 723). Todavia, mais abaixo, eles concluem que "o não investimento, na mesma proporção (das coautorias simples), na coautoria com orientandos parece $(\mathrm{m})$ indicar que a área de educação não aposta nessa forma de 
colaboração científica como uma maneira efetiva de contribuir para o processo formativo dos alunos" (LOPES; COSTA, 2012, p. 725; grifo nosso; trecho entre parênteses incluído). Ora, se o recurso aos números tem valor inferencial, causa espécie que se conclua que a área de educação não aposte num tipo de coautoria com o volume de ocorrências e o aumento percentual de quase $60 \%$ citados. No máximo, os dados permitem afirmar que há maior investimento em coautoria simples, embora haja indícios de mudança desse quadro.

Ademais, se a discrepância acima permite especulações, uma delas seria que professores preferem se associar a professores para aumentar a publicabilidade dos seus textos (VILAÇA; PALMA, 2013). Tal estratégia se coadunaria com uma expectativa que resulta da vigência do que Godoi e Xavier (2012) denominam de lógica anômala do argumento de autoridade sobre a autoridade do argumento, bem como da observação do quadro real dos periódicos, qual seja, de poucos textos publicados por mestrandos e doutorandos, principalmente em periódicos A1, A2 e B1, o que pode levar os professores a pensar que estes tem uma predileção autoral. Até porque "grandes nomes" tendem a gerar mais acessos e citações (citabilidade), o que interessa aos periódicos, fechando outro tipo de círculo vicioso de mútuo interesse (pesquisador-periódico).

Apostar no envio de um texto com um coautor não professor e/ou não doutor traria consigo o risco da redução das chances de publicação, do poder competitivo do produto no mercado de publicações, o que, no contexto atual, é anti-estratégico, algo pragmaticamente desaconselhável. Embora estejamos falando de tendências e possibilidades, na dúvida, melhor não arriscar pagar o preço pela "improdutividade".

Os números também são utilizados para sustentar outras afirmações que serão objeto de uma análise mais detida, haja vista eles poderem não revelar aquilo que os autores inferem. Por exemplo, para Lopes e Costa:

Entre os cinco pesquisadores com maiores índices de produção em coautoria, apenas dois estão entre os cinco pesquisadores com os 
maiores índices de produtividade total do período, o que pode indicar que o aumento da produção em coautoria não é garantia do aumento da produção em geral. Dos cinco pesquisadores com maiores índices de produção, apenas dois têm índices de produtividade em coautoria em valores mais altos que dois artigos por ano. Nem sempre, quando há maior índice de coautoria, há maior índice de produtividade, o que nos leva a considerar que a coautoria não está sendo utilizada obrigatoriamente para ampliar a produção de maneira que atinja os mais altos índices da área (LOPES; COSTA, 2012, p. 722; grifo nosso).

De saída, considerando que um texto sempre possui um endereçamento ainda que potencial e que os autores do texto em questão estão posicionandose num debate que envolve partes discordantes, cabe interrogar contra que autores estão dirigindo a sua argumentação, isto é, quem defende que coautorias são necessárias e meramente uma forma de aumentar a produtividade? Como não são apresentados exemplos de uma suposta corrente extremista, pode ser que a argumentação empreendida não se refira propriamente ao que a literatura crítica especializada tem apontado, a saber, que existem tendências de aumento de coautorias nos últimos anos, justamente a partir do momento em que as lógicas cientométrica e bibliométrica atuais passaram a viger não só no Brasil (GRIEGER, 2005; CARNEIRO, CANGUSSÚ; FERNANDES, 2007; CAMARGO JR.; COELI, 2012), mas também internacionalmente (IOANNIDIS, 2008). Dentro e fora do Brasil, estudiosos do tema identificam fatores que subsidiam o entendimento de que há uma forte associação entre o aumento quantitativo de coautorias e as políticas científicas de avaliação/ hierarquização/distribuição de recursos. Relevantes indícios apontariam para o fato de que coautorias seriam também formadas estrategicamente, isto é, com o intuito de aumentar a produtividade dos pesquisadores, tipo questionável de prática acadêmica (no limite, uma má conduta científica) que não está restrito ao plano nacional (KERBAUY, 2005; IOANNIDIS, 2008) e não pode ser desconsiderado. Conforme Grieger (2005, p. 243), "após o aumento do número de publicações, surgiu a inflação da autoria", fenômenos que se retroalimentam. 
Corroborando isso, John Ioannidis, uma referência no debate crítico acerca da cientometria em vigor e sobre seus efeitos em termos de pressure to publish-or-perish (pressão para publicar ou perecer) e get-cited-or-perish (ser citado ou perecer), afirma que, em um contexto competitivo, em que a promoção de indivíduos e a sobrevivência de equipes e instituições dependem de publicações e citações, "o número médio de autores por artigo é crescente" (IOANNIDIS, 2008, p. 1). Ele ressalta que, embora "isso possa refletir, em parte, o bem-vindo advento de mais esforços de pesquisa colaborativa. No entanto, provavelmente, vários coautores não satisfazem completamente os critérios de autoria" (IOANNIDIS, 2008, p. 1). As chamadas autoria dadivosa (gift authorship) ${ }^{2}$ e honorária (honorary authorship $)^{3}$ têm sido demonstradas repetidamente, pois a sua prática sistemática, ao lado de outras práticas antiéticas, acaba inflando os currículos dos pesquisadores, segundo Ioannidis (2008). Aliás, Lopes e Costa, aparentemente sem se darem conta, citam um caso de autoria honorária, a saber, do "coordenador de um grupo, responsável pela organização do quadro teórico-metodológico de uma linha de pesquisa e pela montagem de toda infraestrutura de um laboratório na área de ciências da natureza, (que) é coautor obrigatório, mas não o principal, dos artigos do laboratório em questão" (LOPES; COSTA, 2012, p. 718; grifo nosso; termo entre parênteses incluído). Para Ioannidis, "o maior perigo é que grupos de pesquisa inescrupulosos, que praticam a gift authorship extensivamente, tornem seus membros inescrupulosos mais competitivos do que cientistas que têm exigentes padrões de autoria" (IOANNIDIS, 2008, p. 6).

2 Multifacetada, pode representar uma estratégia para aumentar as chances de publicação de um texto, nos casos em que coautores famosos são convidados; pode, também, visar à ampliação da network de um pesquisador, na medida em que uma 'autoria de presente' pode estreitar certos laços; à semelhança, tal 'presente' pode, a curto ou médio prazo, contribuir para o incremento curricular do autor dadivoso, já que tente a gerar retribuições.

3 Imposição, explícita ou não, de autoria que um pesquisador, dada a sua posição de prestígio acadêmico-científico, faz a outro pesquisador que está em posição inferior, podendo haver benefício mútuo. 
Segundo Grieger, "com a disseminação da gift authorship, carreiras brilhantes com base em currículos consistentes poderiam ser construídas sem muito esforço" (GRIEGER, 2005, p. 244). Aduzindo um caso abordado por Esteves (2011), em que pesquisadores brasileiros acusados de publicar artigos com imagens adulteradas e resultados falsos são entrevistados, transcrevemos o revelador testemunho de uma coautora dos artigos: "Honestamente, eu não lia todos os trabalhos, mesmo porque eu não entendia muitos detalhes, são coisas muito específicas de química" (s/p.). Sublinhamos que agências nacionais, como a Fundação de Amparo à Pesquisa do Estado de São Paulo (FAPESP) e o Conselho Nacional de Desenvolvimento Científico e Tecnológico (CNPq), demonstram preocupação, proscrevendo práticas como a supracitada por Lopes e Costa (2012). No texto de Santos (2011), publicado no site da FAPESP, lê-se que

ações que, intencionalmente ou por negligência, contrariem esse pressuposto (da autoria justificada) contribuem para o estabelecimento de falsas reputações e para a distribuição cientificamente injustificada de oportunidades e recompensas (s/p.; trecho entre parênteses incluído).

Para o CNPq (2011, p. 2), ressalvado o fato de o texto focalizar autorias fraudulentas devido à prática de falsificação e plágio, "em um ambiente de competição para a obtenção de auxílios financeiros, isso pode significar o investimento em pessoas e projetos imerecidos, em detrimento daqueles que efetivamente são capazes de produzir avanços do conhecimento".

Coautorias entre orientadores e orientandos podem ser forjadas, conforme Carneiro, Cangussú e Fernandes (2007), para ampliar as chances de publicação de textos que, em grande parte ou na sua totalidade, foram escritos por estes, até mesmo alterando a ordem de autoria, a saber, colocando aqueles como autor principal, já que possuem maior capital curricular (VILAÇA; PALMA, 2013); ou para viabilizar a simples submissão do texto, pois há revistas que só aceitam textos de doutores. 
Cabe, outrossim, citar que pesquisadores mostram a importância de enfrentar as várias facetas do problema das coautorias fraudulentas (ELLIOTT; LANDA, 2010; CAMARGO JR.; COELI, 2012). Maddox (1994), percebendo, com clareza, a proporção do problema gerado pela lógica performática que governa a cientometria e bibliometria vigentes, defende que o enfraquecimento do vínculo entre publicação-produtividade e o sucesso pessoal-profissional geraria benefícios imensos, notadamente no tocante ao que denomina de prática generalizada da coautoria espúria. Afirmando que a coautoria não é um dom gratuito (free gift), a Nature (1994) ressalta as armadilhas da coautoria em um contexto competitivo. A magnitude do problema é ratificada pelo fato de alguns dos mais relevantes códigos de conduta científica internacionais (ORI, 2007; ESF, 2011) e nacionais (CNPq, 2011; FAPESP, 2011) contemplarem tais práticas antiéticas.

Como observação epistemológica, destacamos a expressão apenas dois na citação supra (LOPES; COSTA, 2012), questionando o seu valor epistêmico. Ora, se 5 é igual a 100\% de uma amostra, 2 é igual a $40 \%$ da amostra. Tendo em vista a importância científica dos números, cabe questionar a pertinência do uso da expressão apenas dois, já que, percentualmente, tem um valor tão alto. Quer dizer, supondo que a amostra tivesse algum valor estatístico, 40\% revelariam algo distinto do que os autores defendem, o que seria bastante significativo. Embora o alto índice percentual não conteste a conclusão dos autores - até porque, dado ser um truísmo, um percentual bem mais alto, como de 90\%, também não seria - chama atenção o jogo discursivo (des)envolvido.

Além disso, há um aspecto importante no uso dos números pelos autores, a saber, que, estatisticamente, tal uso pouco representa. Os números, como mencionado anteriormente, são utilizados porque supomos que sejam objetivos, reais, imparciais. Contudo, o uso inadequado pode apenas servir para apoiar ideias pré-concebidas. A frequência relativa, no caso do trabalho de Lopes e Costa (2012), foi de pouca utilidade para 
ajudar a entender como o fenômeno se comportou, causando um efeito de demonstração/verdade questionável. A utilização de testes de hipótese é um dos procedimentos fundamentais para que se possa realizar inferência estatística. Outro aspecto relevante diz respeito ao fato de que ao se aplicar um teste de hipótese é possível, tão somente, saber se um determinado resultado é estatisticamente significante e, assim, demonstrar a provável existência de associação entre as variáveis investigadas. Contudo, em que pese a relação de causalidade necessitar da existência de associação entre duas variáveis, tal condição, ainda assim, não bastaria para estabelecê-la (MASSAD et al., 2004; LEVIN, 1987).

Em síntese, a coautoria não é nada em si, isto é, para além de condições concreto-contextuais e implicações subjetivas, nem algo bom, nem prejudicial. Se, por um lado, é fato que coautorias não envolvem sempre uma má prática acadêmico-científica ou têm uma finalidade meramente instrumental, pragmática ou produtivista, podendo, como defendem Lopes e Costa (2012) representar positivas colaborações; por outro lado, é fato que problemas em torno da autoria e coautoria existem, têm relação com a política acadêmico-científica adotada hodiernamente em muitos lugares do mundo, geram consequências importantes e devem ser enfrentados. Dessa forma, os autores estariam na contramão de um movimento global pela integridade científica ao subestimar a existência e relevância desse problema.

Outra conclusão baseada em números que nos parece contestável diz respeito à inexistência de uma lógica produtivista na área de educação. Se, como Lopes e Costa (2012) defendem o produtivismo ser aferido exclusivamente pelo critério do número de produtos em dado período (índice de produtividade bibliográfica), de fato, eles poderiam ter razão. Afinal, a priori, um índice de produtividade de dois artigos por ano, ou até mesmo mais, não deve ser imperiosamente categorizado de produtivismo.

No entanto, a considerar a proposta de Vilaça e Palma (2013), para os quais é necessário distinguir a norma produtividade da norma produtivismo, de modo que esta não é caso de mera aferição quantita- 
tiva, mas envolve outros fatores, tais como formas de fetichização do conhecimento (TREIN; RODRIGUES, 2011; BIANCHETTI; ZUIN, 2012) e do ego e más práticas acadêmico-científicas, os números não são provas incontestes. Assim, a (supostamente) não produtivista marca de 1,6 ou 2 artigos por autor/ano num triênio pode, num olhar mais acurado, revelar outros traços ou indícios. Por exemplo, que o(s) autor(es) compreende(m) a publicação como uma performance individual ou de organizações, tencionando à satisfação de uma cultura de performatividade competitiva sem preocupações mais amplas, coletivas ou sociais do que é produzido e publicado (BALL, 2005). Ou, ainda, que se recorreu a práticas antiéticas, tal como versões requentadas ou maquiadas de um mesmo produto (KUENZER; MORAES, 2005), bem como coautorias indevidas, envolvendo 'escritores e/ou autoria-fantasma' (GRIEGER, 2007; CNPq, 2011) e/ou 'autor honorário' - incluindo o subtipo da troca da ordem autor-coautor(es), por vezes, entre orientador e orientando - visando simplesmente ao sucesso do processo de submissão-avaliação, isto é, à efetiva e performática publicação de um texto em um periódico para fins de adensamento curricular e ampliação das chances de conquistar financiamentos ${ }^{4} \mathrm{e}$ benefícios na carreira profissional em um mundo acadêmico-científico cada vez mais marcado pela competição e seus efeitos ${ }^{5}$ (DE MEIS et $a l ., 2003)$. Embora não haja uma contradição necessária, haja vista pensar e escrever não serem mutuamente excludentes, Roland (2007, p. 425) afirma que "em geral, o discurso científico tem evoluído para um modelo "pronto para escrever" (ready-to-write model), o que tem progressivamente gerado pesquisadores com um falso modelo "pronto para pensar" (ersatz ready-to-think model)".

4 Segundo Gorenstein (2003, p. 129) "em um dos comitês de avaliação do CNPq foram solicitados 437 auxílios, dos quais 267 atingiram os atributos de mérito. Como os recursos eram suficientes apenas para 20 deles, os critérios adotados levaram em consideração, principalmente, o número de publicações e o impacto das revistas onde o solicitante publicou".

5 Conferir relatos em De Meis et al. (2003, p. 1.139). 
Ou seja, o entendimento que sustentamos é que, ainda que um pesquisador tenha um índice de produtividade no triênio considerado bastante baixo, como 0,3 (equivalente a um artigo), se ele se associou a coautores por mera conveniência ou cometeu quaisquer outras más condutas científicas como meios para atingir um fim (de publicar um texto) típico de um contexto pautado pela performatividade, indubitavelmente ele incorreu na prática do produtivismo. Importa ressaltar que não endossamos a tendência de culpabilização individual dos pesquisadores. Para nós, as más condutas não podem ser deslindadas do contexto citado, à semelhança do que argumentam Bianchetti e Zuin (2012). Afinal, em um contexto em que "há uma possibilidade concreta de que as relações sociais autênticas sejam substituídas por relações performativas, em que as pessoas são valorizadas com base exclusivamente na sua produtividade" (BALL, 2005, p. 556), produzir torna-se condição de sobrevivência e desapagamento existencial e profissional.

Dada a complexidade da questão da autoria e da coautoria, porém, mais especificamente, ante a consideração de que (co)autorias indevidas são um tipo de más condutas acadêmico-científicas e que estas constituem o produtivismo, entendemos que o critério quantitativo, numérico é insuficiente, de modo que apelar exclusivamente a ele é uma forma enviesada de abordar o problema. Por isso, erra tanto quem afirma que um número elevado de produções e coautorias significa cominatoriamente que haja produtivismo quanto quem assevera que um número reduzido expressa necessariamente $o$ contrário. Ao invés de generalizações com base numérica ou supostamente estatística, é necessário avaliar com maior acuidade, talvez no caso a caso. Enquanto isso não ocorrer, tememos nossas afirmações podem não revelar a realidade do problema, ou bem agigantando-o, ou bem subestimando-o.

\section{Performatividade: o lugar das negatividades, a importância da dessemelhança e a necessidade de coerência}

A última estratégia argumentativa para a qual chamamos atenção refere-se ao que denominaremos de argumento da simetria para uma 
crítica recíproca. No texto de Lopes e Costa (2012), ele aparece na tentativa de estabelecer uma relação de simetria entre Ball e Lyotard, para, no momento seguinte, apresentar uma afirmação parcial que, para uma terceira pessoa (o leitor), resulte em prova contra a forte crítica desenvolvida pelo primeiro. A sentença em que tal relação de identidade parece ser estabelecida é: "Há os riscos do que vem sendo denominado, com base nos estudos de Lyotard (1986) incorporados por Ball (2003, 2004), de cultura da performatividade" (LOPES; COSTA, 2012, p. 727). O trecho, por sua vez, em que parece haver a tentativa de uma crítica recíproca é: "Mesmo porque a cultura da performatividade para Lyotard não é necessariamente negativa" (LOPES; COSTA, 2012, p. 728).

Stephen Ball é um conhecido pensador que tem se notabilizado por criticar a lógica da performatividade. Ele, ao mesmo tempo em que seguramente incorpora a obra de Lyotard (2011) nos seus escritos, claramente o ultrapassa em vários aspectos, incorporando outros referenciais. Quer dizer, Ball não pode ser subsumido a Lyotard, de tal modo que a crítica a um deles não pode ter efeito recíproco. Lopes e Costa (2012) afirmam que Lyotard não considerava a performatividade algo necessariamente negativo, o que pode sugerir ao leitor que a postura de Ball seria inconsistente, já que divergiria do que seu suposto referencial entende. Isto é, se a performatividade é tida como parcialmente positiva pelo autor que seria a base para Ball, é pertinente prever que o leitor seja induzido a inferir que este autor ou bem não tenha entendido corretamente aquele, ou bem que sua perspectiva seja exagerada ou falha.

De fato, Lyotard (2001) aponta algumas positividades, no sentido foucaultiano (isto é, produtivo), além de linhas de fuga (principalmente pelo conceito de invenção), idem, relativas à lógica operativo-performática. Todavia, ele não deixa de destacar as sérias negatividades (no sentido corriqueiro, algo nocivo) que lhe são inerentes. Partindo da premissa de que Lyotard não caracterizava-se por uma postura cínica, vejamos um trecho no qual, salvo engano, certos termos sugerem importantes negatividades: 
o sistema apresenta-se como a máquina de vanguarda atraindo a humanidade, desumanizando- $a$, para tornar a humanizá-la em outro nível de capacidade normativa. Os tecnocratas declaram não poder fiar-se no que a sociedade declara serem suas necessidades. Eis aí o orgulho dos decisores, e sua cegueira. Este comportamento é terrorista. Entende-se por terror a eficiência oriunda da eliminação ou da ameaça de eliminação de um parceiro fora do jogo de linguagem que se jogava com ele (LYOTARD, 2011, p. 114-115; grifos nossos).

Caracterizar um sistema como insensível e cego às necessidades humanas que não favoreçam a sua eficiência, portanto, um sistema instrumentalizador da vida humana, desumanizador e, no limite, terrorista, que força o indivíduo a se calar ou a dar seu assentimento "não porque ele é refutado, mas ameaçado de ser privado de jogar", dizendo-lhe "adaptai vossas aspirações aos nossos fins, senão" (LYOTARD, 2011, p. 115-116), decisivamente não pode ser uma forma de mostrar as suas positividades, a não ser que aquela premissa seja devidamente refutada.

Os danos causados pela racionalidade funcionalista e instrumentalizadora, pela consequente reificação do humano e de suas relações, têm sido apontados por vários pensadores. Um dos mais ferrenhos críticos é o filósofo alemão Jürgen Habermas, que, em sua teoria crítico-social reconstrutiva (intitulada Teoria da Ação Comunicativo, de 1981), faz uma detalhada investigação do processo de racionalização moderno, diagnosticando alguns dos males gerados pela colonização do mundo da vida pelo sistema. Dentre eles, destacamos a retração do espaço público de discussão política, em razão da paulatina transição para a análise científica e a planificação técnica, que revela as debilidades do modelo tecnocrático de Estado como um órgão meramente administrativo e integralmente racional-instrumental (razão meios-fins) que só pode ser avaliado quanto à eficiência da sua gestão face aos produtos comensuráveis, e não pela justeza ou não das suas decisões, práticas e políticas (HABERMAS, 1997). No contexto da ideologia capitalista, a "política (é) dirigida à resolução de tarefas técnicas que põe entre parênteses questões práticas" 
(HABERMAS, 1997, p. 75), submetendo o marco institucional às coações manipulatórias da administração técnico-operativa. Ainda segundo esse filósofo, "a autocompreensão culturalmente determinada de um mundo social da vida é substituída pela autocoisificação dos homens, sob as categorias de acção racionalidade dirigida a fins e do comportamento adaptativo" (HABERMAS, 1997, p. 74). Observamos, ainda, que Ball (2005) - a partir do filósofo comunitarista canadense Charles Taylor, um crítico neo-aristotélico da modernidade - aponta negatividades, como o instrumentalismo desengajado e desaparecimento de horizontes morais.

Lopes e Costa (2012) defendem, nas últimas linhas do texto, que a lógica operativa da performance (desempenho) não é completamente negativa, única, totalitária, fechada ou estável, posto que pudesse ser subvertida através da alteração das suas regras. Em que pese concordarmos com o âmago dessa ideia, os autores não apresentam exemplos de resistências em que o principal ou único prejudicado não seja o sujeito que tenta resistir, por exemplo, sendo descredenciado de um PPG por 'improdutividade'; ou sendo perseguido e sofrendo retaliações ${ }^{6}$ por denunciar más condutas científicas praticadas, incluindo processos judiciais. Também não são apresentados indícios de que tal lógica esteja em processo de mudança ou arrefecimento, e não de recrudescimento, como a recente proposta do governo federal para reestruturar a carreira docente sugere, tampouco, quais seriam os seus efeitos positivos.

Conforme Alcadipani (2011) argumenta, sublinhando a importância dos ensinamentos provenientes da genealogia do poder foucaultiana, o problemático sistema em vigor é completamente dependente dos pesquisadores, das nossas ações produtivistas, e, na medida em que atende aos anseios de alguns, ele é reiterado e fortalecido.

6 De acordo com o Código de Boas Práticas Científicas da FAPESP (2011, p. 26), “3.3. Nenhum pesquisador deve praticar ou facilitar, por ação ou omissão, qualquer ato que possa ser razoavelmente percebido como retaliatório em relação a quem informe, de boa fé, uma instituição de pesquisa ou a FAPESP acerca da ocorrência de possíveis más condutas científicas ou colabore com sua investigação". 
Considerando os apontamentos críticos que fizemos especialmente na seção "2", cumpre sublinhar algumas afirmações e conclusões problemáticas. A afirmação de que a limitada amostra selecionada, como os autores admitem ser, revela que os pesquisadores que vêm recorrendo à coautoria "são pesquisadores altamente produtivos - portanto, não necessitam da ampliação formal de sua produção" (LOPES; COSTA, 2012, p. 727) não demonstra ou comprova a inexistência de uma cultura da performatividade, na qual coautorias são uma das estratégias de conservatio vitae, ou seja, de autoconservação do indivíduo no mundo acadêmico-científico. Além disso, ao menos aparentemente, ela vai de encontro com a conclusão de que "a produção em coautoria é valorizada nesse grupo de pesquisadores e contribui para aumentar os índices de produção bibliográfica" (LOPES; COSTA, 2012, p. 722; grifo nosso). Afinal, segundo esta afirmação, a coautoria serviu justamente para ampliar a produção dos pesquisadores, o que, deste ponto de vista, teria ajudado a torná-los altamente produtivos.

Cumpre destacar também que há uma aparente antinomia entre o entendimento de que a lógica do desempenho pode conviver com outras lógicas e pode ser alterada - ou seja, ela existe - e a de que foi demonstrado, por meio da amostra analisada, que não há indícios de produtivismo ou performatividade na área de educação. Ademais, a negação da perspectiva da performatividade associada à declaração de que consideram "que o amadurecimento dos grupos de pesquisa na área permite construir mecanismos capazes de minimizar, ou até mesmo impedir, esses riscos" (LOPES; COSTA, 2012, p. 727-728) - por sinal, um entendimento que carece de precisão, já que maturidade é um conceito vago e não há exemplos de quais seriam tais mecanismos - seguida, por seu turno, da assertiva de que "a cultura da performatividade não é necessariamente negativa" (LOPES; COSTA, 2012, p. 728), cria um imbróglio argumentativo, pois:

1. se a cultura da performatividade não existe, não é necessário apostar no amadurecimento dos grupos de pesquisa para mi- 
nimizar ou obstruir seus riscos, já que estes, por conseguinte, inexistiriam;

2. se a performatividade inexiste, por que e como ressaltar as suas positividades? e

3. por fim, se há riscos da cultura da performatividade, é imperioso admitir a existência desta, bem como que ela produz efeitos negativos, como podem ser as coautorias indevidas, não sendo absolutamente positiva.

À vista dessas coisas, a rejeição da perspectiva de Ball soa como a expressão de convicções que, no texto, carecem de justificativas e coerência.

\section{Em suma...}

A nossa argumentação leva a algumas conclusões simples e precisas acerca da importância do tema e do atual estado da arte na educação. Primeiramente, a prática de coautoria é complexa e tem íntima relação com traços do mundo acadêmico-científico no momento corrente, de modo que afirmações que desconsideram ou subvalorizam o contexto cientométrico e bibliométrico tendem a falhar ou, no mínimo, a serem parciais. Destarte, para compreender bem a colaboração por meio de coautorias, há a necessidade de desenvolver abordagens teórico-empíricas cuidadosas e sistemáticas, o que ainda não tem sido feito na área de educação. Cabe, então, aos pesquisadores em educação interessados em estudá-la recorrer à literatura nacional e internacional especializada, sobretudo relativa a áreas em que haja estudos mais bem desenvolvidos, assim como formular estudos empíricos apurados e, talvez, voltados especificamente para as características da área. Tais medidas, em conjunto, permitirão que a(s) prática(s) de coautoria na área de educação seja(m) analisada(s) criteriosamente, gerando inferências fundamentadas e consistentes, revelando positividades e negatividades, bem como modos de lidar com elas, promovendo aquelas e combatendo estas. 


\section{Referências}

ALCADIPANI, R. Resistir ao produtivismo: uma ode à perturbação Acadêmica. Cadernos EBAPE.BR, Rio de Janeiro, v. 9, n. 4, p. 1741.178, Dez. 2011.

BALL, S. J. Profissionalismo, gerencialismo e performatividade. $\mathrm{Ca}$ dernos de Pesquisa, São Paulo, v. 35, n. 126, p. 539-564, 2005. Disponível em: <http://dx.doi.org/10.1590/S0100-15742005000300002>. Acesso em: 17 jun. 2013.

BARTNECK, C.; KOKKELMANS, S. Detecting $h$-index manipulation through self-citation analysis. Scientometrics, v. 87, issue 1, p. 85-98, April, 2011. Disponível em: <http://dx.doi.org/10.1007/s11192-0100306-5>. Acesso em: 17 jun. 2013.

BIANCHETTI, L.; ZUIN, A. A. S. O intelectual universitário e seu trabalho em tempos de "pesquisa administrada". Educação em Revista, Belo Horizonte, v. 28, n. 3, p. 55-75, 2012. Disponível em: <http:// dx.doi.org/10.1590/S0102-46982012000300003>. Acesso em: 17 jun. 2013.

CAMARGO JR., K. R.; COELI, C. M. Múltipla autoria: crescimento ou bolha inflacionária?. Revista de Saúde Pública, São Paulo, v. 46, n. 5, p. 894-900, 2012. Disponível em: <http://dx.doi.org/10.1590/S003489102012000500017>. Acesso em: 17 jun. 2013.

CARNEIRO, M. A. A.; CANGUSSÚ, S. D.; FERNANDES, G W. Ethical abuses in the authorship of scientific papers. Revista Brasileira de Entomologia, São Paulo, v. 51, n. 1, p. 1 - 5, jan./mar. 2007.

CASTIEL, L. D.; SANZ-VALERO, J. Política científica: manejar la precariedad de los excesos y desnaturalizar la ideología "publicacionista" todopoderosa. Salud Colectiva, Lanús, v. 5, n. 1, p. 5-11, jan./ abr. 2009. 
CNPq. Relatório da Comissão de Integridade de Pesquisa do CNPq, 2011. Disponível em: <http://www.cnpq.br/documents/10157/ a8927840-2b8f-43b9-8962-5a2ccfa74dda>. Acesso em: 12 jan. 2013.

DE MEIS, L. et al. The growing competition in brazilian science: rites of passage, stress and burnout. Brazilian Journal of Medical and Biological Research, Ribeirão Preto, v. 36, n. 9, p. 1.135-1.141, set. 2003. Disponível em: <http://dx.doi.org/10.1590/S0100-879X2003000900001>. Acesso em: 17 jun. 2013.

ELLIOTT, C.; LANDA, S. What's wrong with ghostwriting? Bioethics, v. 24, n. 6, p. 284-286, 2010. Disponível em: <http://dx.doi.org/10.1111 /j.1467-8519.2010.01828.x>. Aecesso em: 17 jun. 2013.

ESPOSITO, R. O paradigma da imunização. In: . Biopolítica e filosofia. Lisboa: Edições 70, 2010. p. 73-116.

ESTEVES, B. Os alquimistas. Químicos acusados de forjar resultados de onze estudos colocam o Brasil no mapa da fraude científica mundial. Revista Piauí, São Paulo, Edição 60, p. 48-54, set. 2011. Disponível em: <http://revistapiaui.estadao.com.br/edicao-60/anais-da-ciencia/os-alquimistas $>$. Acesso em: 12 jan. 2013.

EUROPEAN SCIENCE FOUNDATION (ESF). The European Code of Conduct for Research Integrity, march 2011. Disponível em: <http:// www.esf.org/publications/corporate-publications.html>. Acesso em: 12 jan. 2013.

FANELLI, D. Do pressures to publish increase scientists' bias? An empirical support from US states data. PLoS ONE, v. 5, issue 4, p. 1-7, 2010. Disponível em: <http://dx.doi.org/10.1371/journal.pone.0010271>. Acesso em: 17 jan. 2013.

FAPESP. Código de boas práticas científicas, 2011. Disponível em: $<$ http://www.fapesp.br/boaspraticas/codigo_fapesp0911.pdf $>$. Acesso em: 12 jan. 2013. 
FREITAS, M. E. O pesquisador hoje: entre o artesanato intelectual e a produção em série. Cadernos EBAPE.BR, Rio de Janeiro, v. 9, n. 4, p.1.158-1.163, dez. 2011.

GLÄNZEL, W.; SCHUBERT, A. Analyzing scientific networks through co-authorship. In: MOED, H. F. et al. (Ed.). Handbook of quantitative science and technology research. Dordrecht: Kluwer Academic Publishers, 2004. p. 257-276.

GODOI, C. K.; XAVIER, W. G. O produtivismo e suas anomalias. $\mathrm{Ca}$ dernos EBAPE.BR, Rio de Janeiro, v. 10, n. 2, p. 456-465, jun. 2012.

GORENSTEIN, C. Quem paga o impacto? Considerações sobre conflitos de interesses. Revista Brasileira de Psiquiatria, v. 25, n. 3, set. 2003. Disponível em: <http://dx.doi.org/10.1590/S1516$44462003000300002>$. Acesso em: 17 jun. 2013.

GRIEGER, M. C. A. Authorship: an ethical dilemma of science. Sao Paulo Medical Journal, São Paulo, v. 123, n. 5, p. 242-246, set./nov. 2005. Disponível em: <http://dx.doi.org/10.1590/S1516$31802005000500008>$. Acesso em: 17 jun. 2013.

GRIEGER, M. C. A. Escritores-fantasma e comércio de trabalhos científicos na internet: a ciência em risco. Revista da Associação Médica Brasileira, São Paulo, v. 53, n. 3, p. 247-251, maio/jun. 2007. Disponível em: <http://dx.doi.org/10.1590/S0104-42302007000300023>. Acesso em: 17 jun. 2013.

HABERMAS, J. Técnica e ciência como "Ideologia”. Lisboa: Edições 70, 1997.

IOANNIDIS, J. P. A. Measuring co-authorship and networking-adjusted scientific impact. PLoS One, v. 3, issue 7, p. 1-8, jul. 2008. Disponível em: <http://dx.doi.org/10.1371/journal.pone.0002778>. Acesso em: 17 jan. 2013. 
KERBAUY, R. R. Autoria e co-autoria: efeitos negativos e positivos. Estudos de Psicologia, Campinas, v. 22, n. 1, p. 89-94, jan./mar. 2005. Disponível em: <http://dx.doi.org/10.1590/s0103-166x2005000100010>. Acesso em: 17 jan. 2013.

KUENZER, A. Z.; MORAES, M. C. M. de. Temas e tramas na pós-graduação em educação. Educação \& Sociedade, Campinas, v. 26, n. 93, p. 1.341-1.362, set./dez. 2005. Disponível em: <http://dx.doi.org/10.1590/ S0101-73302005000400015>. Acesso em: 17 jan. 2013.

LEVIN, J. Estatística aplicada a ciências humanas. 2. ed. São Paulo: Harbra, 1987.

LOPES, A. C.; COSTA, H. H. C. A produção bibliográfica em coautoria na área de educação. Revista Brasileira de Educação, Rio de Janeiro, v. 17, n. 51, p. 717-730, set./dez. 2012.

LYOTARD, J-F. A condição pós-moderna. 13. ed. Rio de Janeiro: José Olympio, 2011.

MADDOX, J. Making publication more respectable. Nature, v. 369, p. 353, jun. 1994. Disponível em: <http://dx.doi.org/10.1038/369353a0>. Aceso em: 17 jan. 2013.

MASSAD, E. et al. Métodos quantitativos em medicina. Barueri: Manole, 2004.

MELlO, C. M.; CRUBEllate, J. M.; ROSSONI, L. Dinâmica de relacionamento e prováveis respostas estratégicas de programas brasileiros de pós-graduação em administração à avaliação da Capes: proposições institucionais a partir da análise de redes de co-autorias. Revista de Administração Contemporânea, Curitiba, v. 14, n. 3, p. 43-457, maio/jun. 2010. Disponível em: <http://dx.doi.org/10.1590/S141565552010000300004>. Acesso em: 17 jan. 2013.

MIRANDA, A.; SIMEÃO, E.; MUELLER, S. Autoria coletiva, autoria ontológica e intertextualidade: aspectos conceituais e tecnológicos. Ciência da Informação, Brasília, v. 26, n. 2, p. 35-45, maio/ago. 2007. 
NATURE. Pitfalls of co-authorship. Nature, v. 372, p. 390, Dez. 1994. Disponível em: <http://dx.doi.org/10.1038/372390a0>. Acesso em: 17 jun. 2013.

PRATHAP, G.; LEYDESDORFF, L. The world of science according to performance indicators based in percentile ranking normalization. Journal of Scientometric Research, v. 1, issue 1, p. 53-59, Set./Dez. 2012.

QUIMET, M.; BÉDARD, P-O.; GÉLINEAU, F. Are the $h$-index and some of its alternatives discriminatory of epistemological beliefs and methodological preferences of faculty members? The case of social scientists in Quebec. Scientometrics, v. 88, issue 1, p. 91-106, Jul. 2011.

ROLAND, M-C. Publish and perish. Hedging and fraud in scientific discourse. EMBO Reports, v. 8, n. 5, p. 424-428, 2007.Disponível em: $<$ http://dx.doi.org/10.1038/sj.embor.7400964>. Acesso em: 17 jan. 2013.

ROSSONI, L.; GUARIDO FILHO, E. R. Cooperação entre programas de pós-graduação em administração no Brasil: evidências estruturais em quatro áreas temáticas. Revista de Administração Contemporânea, Curitiba, v. 13, n. 3, p. 366-390, jul./ago. 2009.

SANTOS, L. H. L. S. Sobre integridade ética da pesquisa. FAPESP, abril 2011. Disponível em: <http://www.fapesp.br/6566>. Acesso em: 12 jan. 2013.

SERRA, F. A. R.; FIATES, G. G.; FERREIRA, M. P. Publicar é difícil ou faltam competências? O desafio de pesquisar e publicar em revistas científicas na visão de editores e revisores internacionais. Revista de Administração Mackenzie, São Paulo, v. 9, n. 4, p. 32-55, maio/jun. 2008.

SGUISSARDI, V. A avaliação defensiva no "modelo CAPES de avaliação" - É possível conciliar avaliação educativa com processos de regulação e controle do Estado?. Perspectiva, Florianópolis, v. 24, n. 1, p. 49-88, jan/jun. 2006. 
SOUSA, S. Z.; BIANCHETTI, L. Pós-graduação e pesquisa em educação no Brasil: o protagonismo da ANPEd. Revista Brasileira de Educação, Rio de Janeiro, v.12, n.36, p. 389-409, set./dez. 2007.

STENECK, N. H. ORI Introduction to the responsible conduct of research, Aug. 2007. Disponível em: <http://ori.hhs.gov/documents/ rcrintro.pdf $>$. Acesso em: 12 jan. 2013.

TREIN, E.; RODRIGUES, J. O mal-estar na academia: produtivismo científico, o fetichismo do conhecimento-mercadoria. Revista Brasileira de Educação, Rio de Janeiro, v. 16, n. 48, p. 769-819, set./dez. 2012.

VILAÇA, M. M.; PALMA, A. Diálogo sobre cientometria, mal-estar na academia e a polêmica do produtivismo. Revista Brasileira de Educação, Rio de Janeiro, v. 18, n. 53, p. 467-484, abr./jun. 2013.

VILAN FILHO, J. L.; SOUZA, H. B.; MUELLER, S. Artigos de periódicos das áreas de informação no Brasil: evolução da produção e da autoria múltipla. Perspectivas em Ciências da Informação, Belo Horizonte, v. 13, n. 2, p. 2-7, maio/ago. 2008.

Data de registro: 17/09/2013

Data de aceite: 22/07/2015 